\title{
“ESTE MUNDO, SEM ABRIGO”: O NOMADISMO NA POESIA DE JORGE GOMES MIRANDA
}

\author{
Julio Cesar Rodrigues Cattapan ${ }^{1}$
}

RESUMO: Análise do nomadismo urbano na poesia de Jorge Gomes Miranda, poeta português contemporâneo. Extinção dos lugares de afeto e de pertencimento na cidade descrita nessa poesia. Deslocamentos de sujeitos ou personagens em busca de abrigo, de afeto ou do restabelecimento de uma identidade fragmentada. Nomadismo como resistência a uma sociedade de controle. Degradação dos ambientes naturais como perda do último refúgio possível de uma cidade hostil.

PALAVRAS-CHAVE: Jorge Gomes Miranda; poesia portuguesa contemporânea; poética urbana; nomadismo urbano.

\section{“NO SHELTER IN THIS WORLD”: NOMADISM IN THE POETRY OF JORGE GOMES MIRANDA}

ABSTRACT: Analysis of the urban nomadism in the poetry of Jorge Gomes Miranda, a contemporary Portuguese poet. Extinction of the places of affection and belonging in the city described in that poetry. Displacement of subjects and characters in search of shelter, affection or the restoration of a fragmented identity. Nomadism as a resistance to a society of control. Degradation of natural environments as the loss of the last possible refuge from a hostile city.

KEYWORDS: Jorge Gomes Miranda; contemporary Portuguese poetry; urban poetics; urban nomadism.

A poesia contemporânea de temática urbana apresenta frequentemente a cidade como um lugar adverso em que personagens deambulam em busca de algo - ou de um abrigo, ou de afeto, ou mesmo de uma identidade — , num deslocamento incessante que faz pensar no nomadismo como um movimento bastante característico dessa poesia, em substituição à antiga flânerie. Neste artigo propomos analisar esse tipo de movimento na poesia de Jorge Gomes Miranda, poeta português bastante contemporâneo, autor de uma obra poética que já consta de treze livros².

A cidade na poesia de Gomes Miranda é geralmente um lugar inóspito, violento, onde os outros habitantes são uma ameaça em potencial, e a integridade física do corpo está sempre em risco. Nesse ambiente hostil predomina, portanto, uma sensação de

\footnotetext{
${ }^{1}$ Mestre em Literatura Portuguesa pela Universidade Federal Fluminense, onde defendeu a dissertação Como não morrer na cidade - elegia, memória e deslocamentos na poesia de Jorge Gomes Miranda. Este artigo é uma adaptação do segundo capítulo dessa dissertação.

2 Jorge Gomes Miranda nasceu no Porto em 1965 e publicou até o momento os seguintes livros de poesia: $O$ que nos protege (1995), Portadas abertas (1999), Curtas-metragens (2002), A hora perdida (2003), Postos de escuta (2003), Este mundo, sem abrigo (2003), O cacador de tempestades (2004), Pontos luminosos (2004), Requiem (2005), Falésias (2006), O acidente (2007), Velhos (2008), Resgate (2008).
} 
insegurança generalizada, o que é reforçado pela percepção de que ele escapa a qualquer tentativa de controle. Segundo Bernardo Secchi, essa percepção advém do crescimento desmesurado das cidades no século XX, que enfrenta

[...] a perspectiva de um crescimento irrefreável da cidade e o temor de sua dissolução em formas de implantações dispersas das quais é difícil compreender a função e o sentido futuros; [...] o pesadelo de uma metrópole que se torna uma megalópole, lugar da concentração das massas de população cada vez mais imponentes, que perde a própria medida, que se torna desmesurada, estranha à experiência individual e coletiva de seus habitantes, que não é mais possível conhecer e dominar em seus aspectos técnicos e funcionais [...].

A angústia acompanha o século, e a cidade parece ser um dos lugares onde ela é delineada de maneira mais evidente. (SECCHI, 2009, p. 32).

O sentimento de pertencimento e integração a um espaço realiza-se apenas quando o indivíduo é capaz de controlá-lo e organizá-lo de acordo com seus próprios desejos, criando uma relação de identificação. Somente com essa identificação ele se sente seguro para investir afetivamente no espaço, apropriando-se dele como seu lugar de atuação. E essa apropriação pressupõe a possibilidade de agir sobre ele para modificá-lo: "A apropriação, como processo de identificação, é, em certo sentido, um agente transformador, pois ao apropriar-se do espaço o sujeito deixa sua marca ao transformá-lo, iniciando, assim, um processo de reapropriação constante [...]" (GONÇALVES, 2007, p. 29). O crescimento desmedido das grandes cidades contemporâneas impede qualquer tentativa de controle do ambiente urbano por parte do indivíduo, além de quase inviabilizar sua capacidade de transformá-lo. A relação de identificação entre sujeito e cidade fica, portanto, prejudicada. A urbe não oferece a segurança necessária para a criação de raízes e laços de pertencimento. Seu habitante, por consequência, não se sente parte dela, nutrindo a sensação de não ter abrigo seguro num meio que lhe escapa sempre ao controle.

Além disso, a ampliação dos espaços de circulação nas grandes cidades traz consigo a dificuldade de se criar vínculos afetivos com o território, de se encontrar um sentido nos ambientes urbanos e nutrir uma sensação de pertencimento a um lugar. A difusão do automóvel modifica significativamente a paisagem urbana, já que os lugares para habitação e socialização se reduzem em prol do aumento considerável do espaço de circulação. Este torna a cidade menos significativa para as relações humanas, pois impõe um nomadismo que impede a criação de raízes nos territórios em que o sujeito urbano transita. "Não 
lugares", na definição de Augé $e^{3}$, as autoestradas são quase todas iguais, constituem um espaço artificial, transitório e sem identidade marcada, resultando numa paisagem que não fornece pontos de identificação com o homem citadino, nem permite que este nela invista sua afetividade. Os espaços habitáveis e, principalmente, os lugares públicos de reunião coletiva, como as praças e os parques, permitem não apenas que o sujeito crie raízes na paisagem e se identifique com ela, mas também favorecem as interações e a criação de vínculos interpessoais. Já os espaços de circulação, pela velocidade e pressa que impõem, não permitem as interações. O automóvel é a exacerbação e exaltação do individual. A cidade, portanto, perde cada vez mais o seu sentido, visto que este, no que se refere ao espaço, reside no investimento afetivo que o sujeito faz em relação ao meio em que vive.

A sensação de ausência de abrigo comparece com frequência na poesia de Miranda — “não há canto seguro / no mundo" (2003a, p. 25), "Este mundo, sem abrigo" (2003b, p. 17) —, manifestando-se, de modo recorrente, na figura do que se assemelha a um nômade ou andarilho que "sem amparo e abrigo certo / anda pelo mundo" (2003a, 64), numa busca quase sempre frustrada por um lugar que o acolha. No poema "As vinhas da ira", um andarilho procura, numa "cidade devassada", um "sítio para repousar as costas":

\begin{abstract}
Envelhecera. O cabelo começava a ficar ralo e de vários dias a barba, mas a sua expressão conservava ainda estoicamente o vigor e o garbo

do condenado que junto a uma das saídas do metro esperava ser um dia libertado do jugo de lembrar o que via ao redor, na cidade devassada.
\end{abstract}

\footnotetext{
${ }^{3}$ Citando Michel de Certeau, Marc Augé considera que a configuração de um lugar depende da existência de corpos em relação num determinado espaço: "Michel de Certeau vê no lugar, qualquer que seja ele, a ordem 'segundo a qual elementos são distribuídos em relações de coexistência' [...].” (AUGÉ, 2012, p. 52). Por consequência, os não lugares seriam espaços em que os corpos (as pessoas) não entram em relação significativa. São, essencialmente, locais de passagem ou nos quais não se permanece o tempo suficiente para criar vínculos interpessoais, permitindo, quando muito, apenas interações breves e superficiais, incapazes de resistir à fugaz permanência no espaço. Os não lugares são, portanto, propícios à solidão e à incomunicabilidade. Por não permitirem interações duradouras, são também locais em que não se constrói uma história nem se constitui uma identidade a eles vinculadas: "Se um lugar pode se definir como identitário, relacional e histórico, um espaço que não pode se definir nem como identitário, nem como relacional, nem como histórico definirá um não lugar” (idem, p. 73). Augé cita como exemplos de não lugares as vias expressas, os aeroportos, os meios de transporte, os grandes centros comerciais e as grandes cadeias de hotéis. Bastante comuns nas grandes cidades, esses não lugares, por serem apenas locais de passagem, contribuem para configurar um sentimento de não fixação e de não pertencimento a um lugar.
} 
Filho de Deus que de modo sucessivo mentir e escarnecer do próximo não aceitou, procurava agora onde cair vivo,

um sítio para repousar as costas, levado por um cão que com altivez, mas em vão, olhava quem pela escura porta era lançado.

(MIRANDA, 2004, p. 29)

Numa deambulação solitária que parece não ter fim — "há quanto tempo tentas resistir / e caminhas sozinha pela cidade?" (2003a, p. 81) —, essa espécie de estrangeiro definitivo sequer tem sua presença percebida nos lugares que frequenta, amargando um anonimato que o condena à solidão. Como acontece em "A máquina":

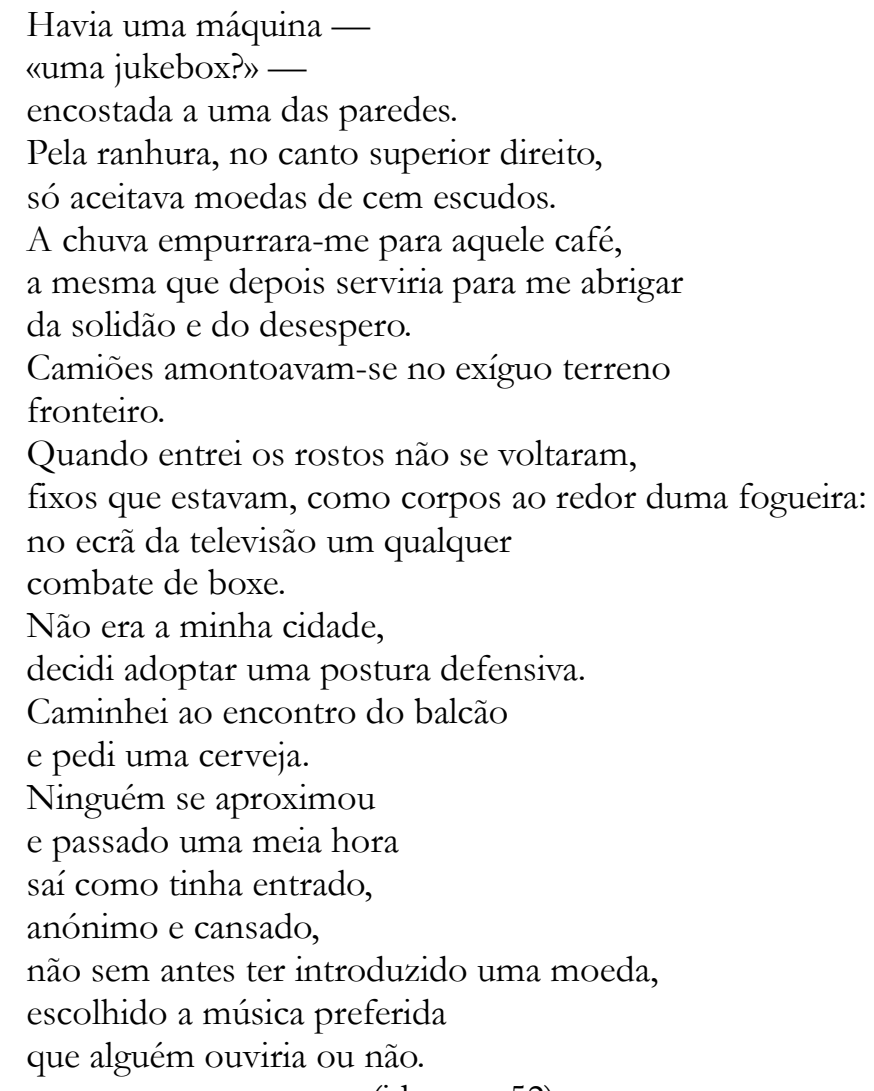

(idem, p. 52)

Amargando a "solidão" e o "desespero", o sujeito tem como "abrigo" a chuva, o que sugere sua dificuldade de encontrar um lugar que o acolha. O café é o lugar da incomunicabilidade, reforçada pela televisão, ironicamente comparada a uma fogueira, que, em tempos remotos, favorecia a socialização em torno do fogo. Estrangeiro na cidade, 
despercebido no ambiente do café, o sujeito tenta inutilmente estabelecer uma interação ao pedir uma cerveja, e termina por retornar à chuva, que ironicamente se revela mais acolhedora do que o próprio café.

A sensação de ausência de abrigo às vezes é alimentada pela condição de um meio urbano em ruínas, como no poema "As vinhas da ira", visto acima, em que o personagem busca refúgio numa "cidade devassada". Compõe as ruínas da urbe a destruição ou extinção dos lugares de afeto, contribuindo para aquela sensação. Em "O insepulto”, os escombros da casa associam-se à aflição da errância:

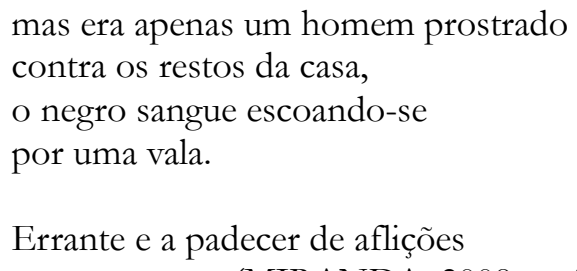

(MIRANDA, 2008, p. 42)

As recordações da infância perdem o lugar de afeto primordial em que se ancoravam: o "dramaturgo lembrou-se da casa / onde viveu a infância, hoje demolida" (MIRANDA, 2004, p. 59). Os lugares que trariam à memória a lembrança dos entes de afeto falecidos já não existem mais, como os que eram frequentados pelo padrinho:

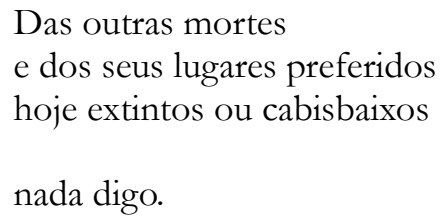

(MIRANDA, 2005, p. 58)

Os lugares amados, associados aos familiares e a experiências afetivas pregressas, encontram-se, frequentemente, destruídos ou próximos do fim. Os sítios que se aprendeu a amar com um ente de afeto — no caso, novamente o padrinho — estão agora ameaçados:

\section{Aprendizagem}

Contigo aprendi a amar os sítios onde ninguém chega para mentir: pequenos cafés, sem televisão

e com uma mesa de bilhar 


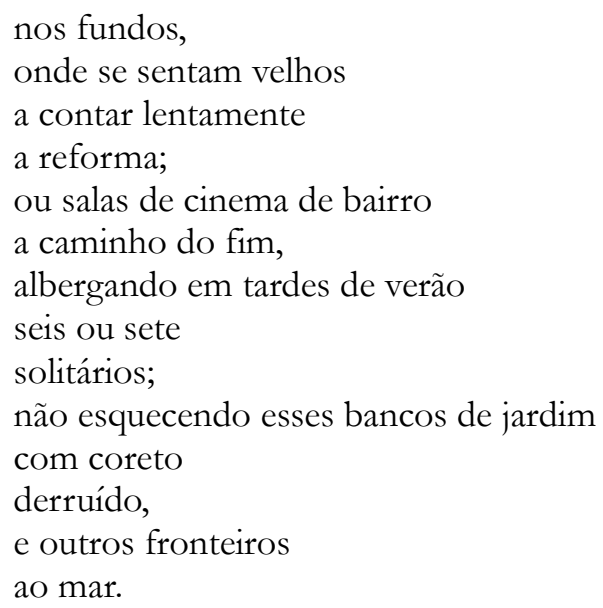

(idem, p. 72)

Os lugares de afeto estão quase todos sob ameaça de extinção: as "salas de cinema de bairro" estão a caminho do fim, provavelmente substituídas por outros tipos de estabelecimento, e o coreto derruído do jardim indicia seu estado de abandono. Perdem-se, portanto, os espaços portadores de uma memória afetiva, onde o afeto que carregam lhes confere a capacidade de oferecer melhor acolhimento, pois fornece a sensação de segurança sob a proteção dos familiares.

De fato, o desvanecimento ou a desvalorização de uma memória afetiva são preocupações recorrentes na poesia de Miranda - “a memória / como letra de câmbio / com os anos perdendo valor” (2003a, p. 49) -, consequências não só da perda dos lugares de afeto que ancoram as recordações, mas também da fugacidade das relações interpessoais nas cidades contemporâneas, impedindo o tempo necessário para a consubstanciação de uma memória:

o amor passageiro que começava num bar, e te esquecia ao meio-dia de domingo, ao abandonar o quarto

(MIRANDA, 2004, p. 52)

Outrora procuravas o instante sereno nos olhos de quem te desejava, agora o que provoca deleite nos de quem vai esquecer-te.

(MIRANDA, 2003a, p. 37) 
A perda dos lugares de afeto e o desvanecimento da memória afetiva associam-se, por sua vez, a uma fragmentação da identidade, outro tema presente na poesia de Miranda. Em "Diálogo com a morte", o sujeito tenta reconstituir uma identidade em pedaços:

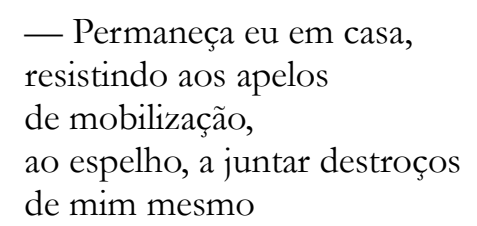

(MIRANDA, 2003b, p. 67)

O homem já não consegue se reconhecer, já não é capaz de identificar o que constitui sua própria subjetividade:

De súbito, sem curiosidade descobrimos
que tudo nos assusta um pouco mais e
pela manhã não fazemos
a mínima ideia de quem somos.

(MIRANDA, 2003c, p. 81)

A percepção da cidade como ameaça e a perda dos lugares de afeto dificultam ao citadino o sentimento de pertencer ao espaço urbano. O pertencimento a um lugar (ou a lugares) é um dos elementos essenciais para a constituição de uma identidade estável. Sem um território seguro e coeso com o qual estabeleça relações de afeto, a identidade não tem onde se ancorar e, por consequência, fragmenta-se. Halbwachs observa que o sentimento de unidade do eu é condicionado pelo pertencimento a lugares: "O que chamamos de sentimento da unidade do nosso eu, em que às vezes enxergamos um princípio original de coesão dos estados, no fundo não é senão a consciência que temos a cada instante de pertencer ao mesmo tempo a diversos ambientes [...]" (HALBWACHS, 2003, p. 64). Segundo Rogério Haesbaert, a fragmentação identitária na contemporaneidade associa-se estreitamente à diluição de uma base territorial:

[...] se no passado podíamos estabelecer identidades mais estáveis e buscávamos referenciais com uma base territorial mais concreta em nossos processos de identificação social, acreditando até mesmo numa coerência obrigatória entre coesão territorial e identidade cultural, neste final de século $[\mathrm{XX}]$ o que parece dominar é a fragmentação identitária. (HAESBAERT, 1999, p. 186) 
Com efeito, o nomadismo na poesia de Miranda surge também como parte de uma busca por identidade numa urbe que não oferece uma base territorial segura. Em "Comédia humana", a perambulação de um personagem andarilho pela cidade é comparada à tentativa de reconhecer o próprio rosto no espelho, numa busca por si mesmo:

Conheci-o, andava ele, sem sítio onde cair vivo, pelas ruas, tentando infiltrar-se no meio de grupos de árvores, perseguindo olhares e gestos na memória, como um louco que diante de um espelho de bolso vai reconstituindo as suas feições. (MIRANDA, 2003b, p. 61)

Como se pode perceber pelo que foi exposto até aqui, o nomadismo envolve uma busca angustiada por algo que nunca se alcança, o que diferencia radicalmente o nômade da figura do flâneur, outro tipo de caminhante urbano, muito comum na literatura do século XIX e início do $\mathrm{XX}^{4}$. A flânerie envolve, sobretudo, a fruição estética dos elementos da cidade, numa perambulação despreocupada, sem destino fixo nem objetivo definido. Segundo Sansot, a flânerie é acompanhada de uma certa alegria, que reside "na caminhada em si mesma, numa respiração livre, num olhar que nada ofusca, no sentimento de estar à vontade no mundo, como se fosse legítimo que dele desfrutássemos" (SANSOT, 2000, p. $35)$.

Um sentimento que certamente não cabe ao nômade de Miranda é o "estar à vontade no mundo". De fato, sua angústia provém justamente da sensação de ser um estranho no meio urbano, de se sentir ameaçado por ele, de nele não encontrar um lugar de acolhimento e abrigo onde possa se fixar e enraizar sua identidade. $\mathrm{O}$ nomadismo não é uma perambulação despreocupada ou um passeio pela cidade, mas uma busca aflita por algo que sempre escapa: busca por abrigo, por afeto, por si mesmo ${ }^{5}$. Trata-se, portanto, de

\footnotetext{
${ }^{4}$ Julgamos importante estabelecer a distinção, pois a flânerie consagrou-se na literatura, desde o século XIX, como a forma mais reconhecida de caminhada pelas ruas da cidade. A figura do nômade, no entanto, parecenos mais característica da poesia mais recente. Segundo Ida Alves, na poesia portuguesa contemporânea de viés urbano, "observamos uma atenção mais evidente sobre subjetividades que se figuram nas experiências de mobilidade, errância, travessia e nomadismo nas cidades” (ALVES, 2013).

5 Tomamos aqui como referência as duas primeiras acepções da palavra "nômade" no dicionário Aurélio: "1. Diz-se das tribos ou povos errantes, sem habitação fixa que se deslocam constantemente em busca de alimentos, pastagens, etc. 2. Diz-se de indivíduo de uma dessas tribos ou povos." (Ed. Positivo, 2009, p. 1406). O nomadismo, portanto, pressupõe uma busca interminável por atender a necessidades básicas de sobrevivência. No entanto, em Miranda ele assume uma maior dramaticidade, pois não é uma busca coletiva
} 
um movimento impulsionado por uma falta que se procura inutilmente preencher, o que engendra um deslocamento sem fim e sem possibilidade de apaziguamento interior.

Não nos cabe aqui investigar e determinar as causas do nomadismo na poesia contemporânea. Parece-nos, no entanto, que o crescimento desmesurado e caótico das metrópoles dificulta a fruição estética dos elementos urbanos, que pressupõe uma certa atitude contemplativa. A redução dos passeios públicos em prol dos espaços de circulação de automóveis, somada ao aumento desproporcional da aglomeração de pedestres, quase impossibilita a perambulação livre pelas calçadas e a contemplação dos elementos presentes na urbe. Outro fator que dificulta a flânerie é a velocidade imposta pela circulação de pessoas, veículos e informações nas grandes cidades atuais, subtraindo ao citadino o tempo necessário para a fruição. A cidade, portanto, perde gradativamente sua capacidade de proporcionar prazer estético para se tornar, cada vez mais, um lugar caótico do qual se deseja evadir, o que favorece a configuração de uma espécie de sentimento nômade.

Além da procura por um abrigo ou por uma identidade, a busca frustrada e interminável por afetos é outro motivo importante do deslocamento nômade na poesia de Miranda, consequência do que seria uma crise das relações afetivas nos grandes centros urbanos. Em “Western”, um personagem solitário busca uma satisfação amorosa que se afigura impossível na prática, realizando-se apenas no campo da ficção e da imaginação:

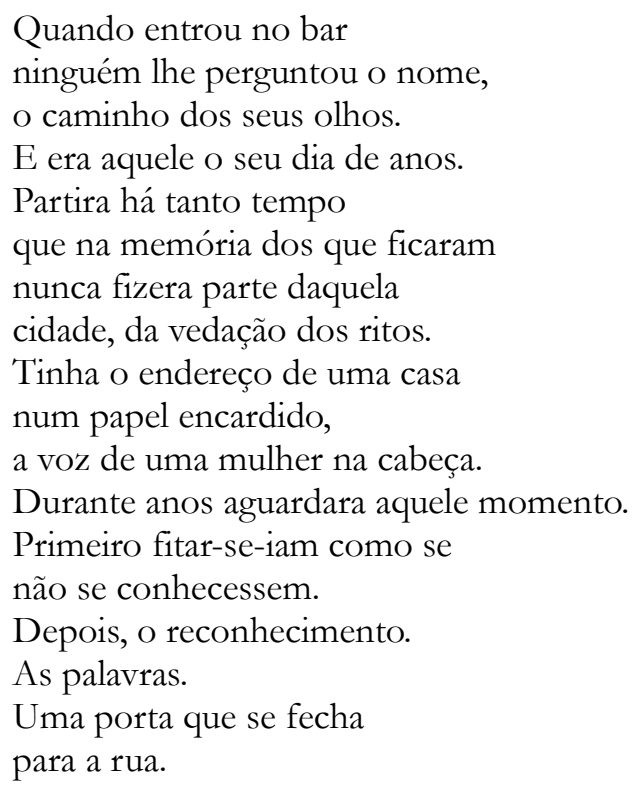

ou comunitária, mas de um indivíduo que se encontra irremediavelmente sozinho, contando apenas consigo mesmo e com sua própria sorte para garantir sua sobrevivência num meio urbano inóspito. 
A camisa entreaberta.

Uma mão que se aproxima.

Olhou ao redor de si.

Era o único na sala.

O genérico estava quase no fim.

Deixou-se ficar um pouco mais

afundado na cadeira.

$\mathrm{Na}$ véspera, prendera nos dedos

este último instante do filme

até que a luz ensurdecedora

de uma lanterna o expulsara.

Essa mão que se aproxima.

A música. Os risos.

Tudo o que não tinha na sua vida.

(MIRANDA, 2002, p. 44-45)

Se algum dia o personagem fez parte de uma comunidade, ou se teve raízes em algum lugar, essa relação de pertencimento já se perdeu, não restando sequer a lembrança de sua existência na memória dos moradores da cidade. Desvinculado de um território, ele se sente estrangeiro mesmo onde um dia habitou. Como o sujeito do poema "A máquina", visto mais acima, ele amarga o anonimato, a solidão e a indiferença de um mundo para o qual sequer parece existir. Levando uma vida esvaziada de afetos, a experiência amorosa apresenta-se-lhe como uma possibilidade remota, num reencontro com um amor perdido que se realiza apenas imaginariamente. Resta-lhe vivenciar o afeto de modo mediado e virtual, entrando ficcionalmente no mundo onírico do cinema. No único momento em que estabelece uma interação, ou é percebido por alguém, é para ser expulso da sala de cinema pelo lanterninha. Quer viver uma história romântica, mas sua vida assemelha-se mais a um western norte-americano, em que é comum a presença de um pistoleiro andarilho, sempre estrangeiro nas cidades que frequenta, incapaz de se adaptar aos códigos sociais e ser aceito numa comunidade. No entanto, sua entrada no bar tem efeito irônico, pois, se por um lado remete à entrada triunfal dos pistoleiros do western em bares de cidades desconhecidas, seguros de si mesmos e temidos pelos frequentadores do ambiente, por outro lado acaba por se revelar a chegada de um personagem apagado, ignorado, emocionalmente fragilizado, numa busca frustrada por uma experiência afetiva.

Em alguns poemas, o nomadismo parece motivado por um desejo de fuga. $\mathrm{O}$ errante noturno de "O relatório", por exemplo, tenta inutilmente escapar de um cotidiano 
burocrático e opressor, representado pelas exigências de um trabalho desprovido de sentido e interesse:

«Vai fechar!

Paga ou ponho na conta?»

A voz cavernosa e familiar

do empregado distrai-o por momentos

das imagens roufenhas da televisão:

manobras militares, uma parada,

tanques alinhados.

Avistado pela porta entreaberta um vulto

atrasado arremessa um convite.

Sai para a rua,

mas não por muito tempo.

Eis que se abriga no Mau-Mau:

o incêndio extinto dos corpos

na pista

humedecendo cigarros,

o asilo do sexo ao balcão;

os elevados decibéis curvam-no,

quando se erguer,

a cabeça para trás,

os olhos cor de fogo-de-artifício,

ninguém reconhecerá mais

na gentileza da voz

a ferrugem de uma canção.

Ao seu redor, abraços,

abraça também quem mais tarde

junto ao rio o empurrará.

No pulso um vaga-lume acende

o riso. Incontrolável.

A esta hora, se se apressar poderá beber ainda mais uma cerveja no Indústria.

Cruza-se com um grupo de pescadores

que sem redes respondem à sua saudação.

Sete e meia da manhã.

Não tarda as confeitarias abrir-se-ão

e tomará o pequeno-almoço.

Antes de passar por casa

para um banho rápido e mudança de roupa.

Da janela do escritório um cartaz

publicitário

instiga-o a novas e irremediáveis aventuras.

Atende o telefone.

Uma voz conhecida e estafada

pergunta: «Acabou o relatório que lhe pedi ontem?»

Desliga.

(MIRANDA, 2003b, p. 22-23) 
Não se trata, evidentemente, de um nomadismo em sentido estrito: o personagem tem endereço e trabalho fixos. No entanto, tampouco se trata de flanerie, pois sua andança pelas ruas da cidade não é acompanhada de um prazer estético, mas atravessada pelo desejo de evasão do cotidiano por meio da ingestão excessiva de bebidas alcoólicas. Além disso, a flânerie ocorre geralmente a céu aberto, e o andarilho do poema busca refúgio nos bares. $\mathrm{O}$ personagem parece situar-se, portanto, a meio caminho entre o nômade e o flâneur. É movido pelo desejo de "novas e irremediáveis aventuras", mas que resulta de uma tentativa de fuga de uma vida cotidiana que o oprime. Há uma angústia característica do nomadismo, sorrateira e quase imperceptível, que subjaz às suas perambulações noturnas pela cidade.

Há, portanto, nesse poema, um movimento motivado pelo desejo de libertação de uma rotina burocrática. De fato, numa interpretação do nomadismo que foge à negatividade que lhe é comumente atribuída, Maffesoli defende que, no mundo contemporâneo, o deslocamento nômade constitui uma espécie de resistência contra as tentativas de dominação do sujeito empreendidas por uma sociedade de controle; a fixação do indivíduo num lugar conhecido é indispensável para que o Estado possa vigiá-lo e controlá-lo:

Será que o drama contemporâneo não vem do fato de que o desejo de errância tende a ressurgir como substituição, ou contra o compromisso de residência que prevaleceu durante toda a modernidade? [...] foi característico da modernidade querer fazer tudo voltar a entrar na ordem, codificar e, stricto sensu, identificar. [...] Michel Foucault e os trabalhos que ele inspirou mostraram bem como, no que concerne à produção, aos costumes, à saúde, à educação, à vida sexual, em resumo para tudo que se convencionou chamar de social, as massas foram domesticadas, assentadas no trabalho e destinadas à residência. [...] Fixar significa a possibilidade de dominar. [...] A regulamentação da "circulação", a boa gestão das disfunções ou dos acidentes que ela não deixa de induzir permanecem, de antiga memória, a preocupação essencial do poder. [...] Cada coisa, cada um estando fixado em um determinado lugar, nada de arriscado ou imprevisível pode sobrevir. (MAFFESOLI, 2001, p. 22-26)

Por vezes encontramos na poesia de Miranda o desejo irrealizável de fugir do domínio opressor da cidade. Em "O deus abandona o poeta", a fuga dos condicionamentos sociais urbanos é uma possibilidade que não existe mais, e, mesmo quando ainda existia, ela parecia constituir uma perambulação incapaz de sair dos limites físicos impostos pela urbe: 
Debruçados para a rua, aceso o último cigarro, exigimos à vida — serpente emplumada de respostas vãs a perguntas inúteis um tempo de exceção, uma passagem por onde regressem o perigo, a beleza e a desordem dessas esplêndidas noites de Verão em que íamos pelas ruas da cidade foragidos de cercos, domínios e exclusão.

(MIRANDA, 2003b, p. 43)

De fato, quase não há mais espaços alternativos à cidade. À exceção de seus três primeiros livros, em que ainda aparecem ambientes naturais preservados, na poesia de Miranda o campo e a natureza - lugares que numa tradição literária ofereciam refúgio contra uma cidade corrompida ${ }^{6}$ - encontram-se irremediavelmente degradados ou perdidos, vítimas da industrialização ou da invasão de um meio urbano em expansão:

\begin{abstract}
A sua vida? Desgovernada carruagem de comboio por uma paisagem periférica e industrial, vencida há muito a bucólica representação do país: campos, vales e montanhas calcinados.
\end{abstract}

(idem, p. 61)

A natureza poluída e agonizante é uma imagem frequente: "O rio esboroado / por descargas poluentes erra // numa apagada mudez sem destino” (MIRANDA, 2004, p. 43). Os ambientes naturais existem somente num passado idílico que não é mais possível recuperar. Sua destruição significa a perda de um lugar de afeto em que se ancorava uma memória afetiva e familiar:

\section{INVESTIGAÇÃO}

Quem ocultou, quem foi desleal permitindo que o alegado poluidor não fosse punido? Desnecessário esperar pela conclusão de inquéritos que terminam

\footnotetext{
${ }^{6}$ Raymond Williams mostra-nos como o campo é tradicionalmente representado na literatura como uma espécie de reservatório de valores e virtudes que não existem mais no meio urbano. A salvação para o homem citadino corrompido é estabelecer elos com o campo, onde é possível reencontrar a inocência perdida na cidade: "E a vida rural, tal como é tradicionalmente considerada, é aqui uma alternativa inocente à ambição, ao tumulto e à guerra" (WILLIAMS, 2011, p. 46).
} 
com as provas destruídas

ou arquivadas.

Antes, deves seguir, sem escolta, os indícios:

o rio onde mergulhavas com as primas

nas férias grandes, encandeado,

jaz agora pela estultícia obscurecido.

Nas oleosas pedras o olhar vítreo de peixes, moedas e preservativos.

Uma cidade transitória, encurralada.

Talvez tenhas tempo ainda para

não aumentar a modorra

das conversas

em derruídos jardins.

(MIRANDA, 2003a, p. 86)

O ambiente natural constituía um refúgio, durante as "férias grandes", de uma "cidade transitória, encurralada"; era o lugar, por oposição a essa cidade, da permanência ou fixação, e da liberdade. Nele se constituiu e se ancorou uma memória afetiva de infância; era, portanto, um espaço de construção de afetos, onde se formaram algumas das balizas que sustentariam a identidade do sujeito. Mas agora esse ambiente natural foi degradado, o que impossibilita reconhecê-lo como o lugar de afeto da infância. A memória e a identidade perdem uma das suas balizas espaciais. Além disso, sua destruição significa a ausência de refúgio da cidade, a condenação do sujeito a permanecer "encurralado" no meio urbano.

Em “Um poema conservador", a degradação do campo é sentida não apenas como a perda de um lugar de afeto, mas também como um sério abalo na capacidade do sujeito de conferir sentidos ao mundo:

Perdi o meu lugar, o meu lugar preferido.

Era uma curva de caminho,

em terra batida

destruída para construírem uma auto-estrada

onde outros perderam a vida.

Primeiro poluíram o rio,

depois chegaram as máquinas e deceparam

um renque de carvalhos centenários;

muito perto, começaram as explosões,

extraíam granito do monte

para construir casas na Alemanha.

Quando nas férias escolares regressei do colégio

já não encontrei razão alguma para sair para os campos,

para o monte, apesar dos rogos dos amigos e

das investidas do cão.

Tudo me parecia sem sentido. Disforme.

[...] 


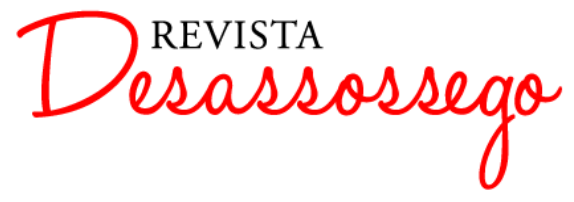

DESASSOSSEGO 13 | JUN/2015 | ISSN 2175-3180

DOI: http://dx.doi.org/10.11606/issn.2175-3180.v7i13p120-135

Perdi o meu lugar, o meu lugar preferido.

Como quem num incêndio perde a casa.

(MIRANDA, 2003b, p. 31)

Existente agora apenas no que restou das lembranças afetivas do sujeito, o campo da infância era um lugar que fornecia o abrigo e o sentimento de pertencimento que a cidade não pode mais oferecer. Ele propiciava, portanto, a construção de uma identidade estável e a possibilidade de atribuir sentidos à existência. Com a sua destruição, o sujeito lírico perde suas raízes, seu vínculo afetivo com um território e o elo que sustentava suas relações de afeto, representadas pelos amigos e pelo cão. Consequentemente, o sentido da própria vida é abalado, tudo parecendo "sem sentido" e "disforme". Perde, enfim, um lugar para habitar, como atestam os versos finais do poema.

É sintomático associar essa percepção do campo como o lugar de abrigo perdido com a figura do nômade desenraizado do ambiente urbano. Como se a perda da natureza fosse a destruição do último refúgio possível, condenando o homem a uma errância interminável na cidade, numa busca angustiada por abrigo, por afeto e pelo restabelecimento de sua identidade fragmentada, num forte indício do esfacelamento das subjetividades e da crise das relações humanas na grande cidade contemporânea.

\section{REFERÊNCIAS BIBLIOGRÁFICAS}

ALVES, Ida. "Paisagens em movimento em alguma poesia portuguesa (anos 70 e mais)". Conferência no II Simpósio Internacional de Literatura, Cultura e Sociedade. Universidade Federal de Viçosa, 7 de agosto de 2013.

AUGÉ, Marc. Não lugares: introdução a uma antropologia da supermodernidade. Trad. Maria Lúcia Pereira. Campinas: Papirus, 2012.

GONÇALVES, Teresinha Maria. Cidade e poética: um estudo de psicologia ambiental sobre o ambiente urbano. Ijuí: Ed. Unijuí, 2007.

HAESBAERT, Rogério. "Identidades territoriais". In: ROSENDAHL, Zeny; CORREAA, Roberto Lobato (Orgs.). Manifestações da cultura no espaço. Rio de Janeiro: EdUERJ, 1999.

HALBWACHS, Maurice. A memória coletiva. Trad. Beatriz Sidou. São Paulo: Centauro, 2003. MAFFESOLI, Michel. Sobre o nomadismo. Trad. Marcos de Castro. Rio de Janeiro: Record, 2001.

MIRANDA, Jorge Gomes. Curtas-metragens. Lisboa: Relógio D’Água, 2002. Postos de escuta. Lisboa: Presença, 2003a. 
. Este mundo, sem abrigo. Lisboa: Relógio D’Água, 2003b.

- A hora perdida. Porto: Campo das Letras, 2003c.

. Pontos luminosos. Lisboa: Averno, 2004.

. Requiem. Lisboa: Assírio \& Alvim, 2005.

. Velhos. Vila Real: Teatro de Vila Real, 2008.

SANSOT, Pierre. Du bon usage de la lenteur. Paris: Éditions Payot \& Rivages, 2000.

SECCHI, Bernardo. A cidade do século vinte. Trad. Marisa Barda. São Paulo: Perspectiva, 2009.

WILLIAMS, Raymond. O campo e a cidade na história e na literatura. Trad. Paulo Henriques Britto. São Paulo: Companhia das Letras, 2011. 